\title{
Optimal Integration of Building Heating Loads in Integrated Heating/Electricity Community Energy Systems: A Bi-Level MPC Approach
}

\author{
Jin, Xiaolong; Wu, Qiuwei; Jia, Hongjie; Hatziargyriou, Nikos D.
}

Published in:

IEEE Transactions on Sustainable Energy

Link to article, DOI:

10.1109/TSTE.2021.3064325

Publication date:

2021

Document Version

Peer reviewed version

Link back to DTU Orbit

Citation (APA):

Jin, X., Wu, Q., Jia, H., \& Hatziargyriou, N. D. (2021). Optimal Integration of Building Heating Loads in Integrated Heating/Electricity Community Energy Systems: A Bi-Level MPC Approach. IEEE Transactions on Sustainable Energy, 12(3), 1741 - 1754. https://doi.org/10.1109/TSTE.2021.3064325

\section{General rights}

Copyright and moral rights for the publications made accessible in the public portal are retained by the authors and/or other copyright owners and it is a condition of accessing publications that users recognise and abide by the legal requirements associated with these rights.

- Users may download and print one copy of any publication from the public portal for the purpose of private study or research.

- You may not further distribute the material or use it for any profit-making activity or commercial gain

- You may freely distribute the URL identifying the publication in the public portal 


\title{
Optimal Integration of Building Heating Loads in Integrated Heating/Electricity Community Energy Systems: A Bi-Level MPC Approach
}

\author{
Xiaolong Jin, Member, IEEE, Qiuwei Wu*, Senior Member, IEEE, Hongjie Jia, Senior Member, \\ IEEE, Nikos D. Hatziargyriou, Fellow, IEEE
}

\begin{abstract}
This paper proposes a bi-level optimal integration scheme for buildings' space heating loads in the integrated community energy system (ICES). The optimal integration scheme consists of an efficient energy management method and a heating pricing method for the ICES with buildings. At the upper level, the ICES operator optimizes the schedules of energy generation and supply, and the heating prices to buildings to maximize its profit. At the lower level, consumers in buildings optimize the water flow rates in the radiators to minimize their heating costs. The thermal dynamics of the building with controllable indoor radiators is modeled using the model of Resistor-Capacitor thermal network. Moreover, the model predictive control (MPC) is integrated with the bi-level optimization to achieve economic and reliable scheduling of the ICES and buildings in the presence of uncertainties. The bi-level MPC optimization is reformulated as an MPC based mixed-integer linear program using the KarushKuhn-Tucker optimality conditions and several linearization techniques. Numerical studies show that the bi-level MPC method can obtain a balanced scheduling scheme between the energy costs of consumers in buildings and the ICES operator's profits. The MPC method can ensure higher profits of the ICES operator and simultaneously, lower energy costs of consumers in buildings.
\end{abstract}

Index Terms - Bi-level optimization, buildings, heating price, integrated community energy systems, model predictive control, thermal dynamics

\section{NOMENCLATURE}

Sets and Indices:

$H_{k}^{c}$

Set of the time slots in $k^{\text {th }}$ control horizon

$H_{k}^{p}$

Set of the time slots in $k^{\text {th }}$ prediction horizon

$k$

Index of control horizon and prediction

horizon in one day

$N^{b c} \quad$ Set of consumers in buildings

$N^{\text {node }}, N^{\text {pipe }} \quad$ Set of heating nodes and heating pipelines

$n_{h} \quad$ Number of control/ prediction horizon in one day

$N_{c}, N_{p} \quad$ Number of time slots of each control horizon/ prediction horizon

Parameters and constants:

$A w^{i, j} \quad$ The area of wall separating the heating zone $i$ and the heating zone $j\left(\mathrm{~m}^{2}\right)$

$A^{\text {win }}$ Window area of the heating zone $\left(\mathrm{m}^{2}\right)$

$C e_{t}^{\text {sale }}$ Electricity sale price of the ICES operator at time $t(\$ / \mathrm{kWh})$

$\mathrm{X}$. Jin and Q. Wu are with the Center for Electric Power and Energy (CEE), Department of Electrical Engineering, Technical University of Denmark (DTU), 2800 Kgs. Lyngby, Denmark (e-mail: xiajin@elektro.dtu.dk, qw@elektro.dtu.dk).

H. Jia is with the Key Laboratory of Smart Grid of Ministry of Education, Tianjin University, Tianjin, 300072, China (e-mail: hjjia@tju.edu.cn).

Nikos D. Hatziargyriou is with the School of Electrical and Computer Engineering, National Technical University of Athens (NTUA), 15773 Athens, Greece (e-mail:nh@power.ece.ntua.gr).

Corresponding author: Q.Wu, qw@elektro.dtu.dk.
$C e_{t}^{b u y_{-} O}$ ICES operator's purchase prices of $C h_{t}^{b y} \_$, electricity/heating/gas from the upper energy $\mathrm{Cg}_{t}^{\text {buy_O} O} \quad$ systems at time $t(\$ / \mathrm{kWh})$

$C h_{t}^{b u y_{-} U} \quad$ Consumers' heating purchase price from the upper energy systems at time $t(\$ / \mathrm{kWh})$

$\mathrm{Cr} \quad$ Heat capacity of the heating zone $(\mathrm{J} / \mathrm{K})$

$C w^{i, j} \quad$ Heat capacity of the wall separating the heating zone $i$ and the heating zone $j(\mathrm{~J} / \mathrm{K})$

$d \quad$ Inner pipe diameter (m)

$L_{l} \quad$ Pipe length (m)

$P_{n, t}^{e, L}$

$P_{t}^{e, L_{-} O}, P_{t}^{h, L_{-} O}$ Total electricity/heating loads of non-building connection nodes of the ICES at time $t(\mathrm{~kW})$

$P_{t}^{P V}, P_{t}^{\text {wind }} \quad$ Power output of photovoltaic generation and wind generation $(\mathrm{kW})$

$\operatorname{Qrad}^{i, j} \quad$ Radiative heat flux density of the wall $\left(\mathrm{W} / \mathrm{m}^{2}\right)$

$Q^{\text {win }}$

Radiative heat flux density of the window $\left(\mathrm{W} / \mathrm{m}^{2}\right)$

$Q^{i n t} \quad$ Internal heat gain of the heating zone $(\mathrm{kW})$

$r^{i, j}$

$R w^{i, j}$ Identifier of sunlit wall

Thermal resistance of the wall separating the heating zone $i$ and the heating zone $j(\mathrm{~K} / \mathrm{kW})$

Rwin

$T_{s}, T_{r}$

$T_{t}^{\text {out }}$

$Y_{H D N}$

$\alpha^{i, j}$ Thermal resistance of the window $(\mathrm{K} / \mathrm{kW})$ Temperature of supply water and return water in the heating distribution network $\left({ }^{\circ} \mathrm{C}\right)$

Outdoor temperature at time $t\left({ }^{\circ} \mathrm{C}\right)$

Incidence matrix of the heating distribution network

Radiative heat absorption coefficient of the wall separating the heating zone $i$ and the heating zone $j$

$c_{p} \quad$ The specific heat capacity of water $\left[\mathrm{J} /\left(\mathrm{kg} \cdot{ }^{\circ} \mathrm{C}\right)\right]$

$\eta_{e}, \eta_{h} \quad$ Conversion efficiency of gas into electricity and heating through the combined heat and power (CHP) unit

Water density $\left(\mathrm{kg} / \mathrm{m}^{3}\right)$

$\rho$

$\kappa_{l}$

$\tau^{\text {win }}$

Variables:

$\mathrm{Ch}_{t}^{\text {sale }}$

Friction factor

The transmittance of window

Heating sale price of the ICES operator at time $t(\$ / \mathrm{kWh})$

$m_{l, t}^{p i p e}, m_{n, t}^{\text {node }}$

Water flow rates of pipe $l$ and node $n$ at time $t$ $(\mathrm{kg} / \mathrm{s})$

$m_{t}^{r} \quad$ Water flow rate in the radiator at time $t(\mathrm{~kg} / \mathrm{s})$

$P_{t}^{e}, P_{t}^{h}, P_{t}^{g} \quad$ ICES operator's electricity/heating/gas purchase at time $t(\mathrm{~kW})$ 


$P_{t}^{c h p}$
$P_{t^{h p}}$
$P_{t}^{\text {loss }}$
$P_{n, t}^{h, L}$
$P_{n}, Q_{n}$
$p_{h, t}$
$T w^{i, j}$
$T_{t}^{r o o m}$
$V_{n}$

Power generation of the CHP unit at time $t$ $(\mathrm{kW})$

Power consumption of the heat pump at time $t$ $(\mathrm{kW})$

Power loss of electricity distribution network at time $t(\mathrm{~kW})$

$P_{n, t}^{h, L} \quad$ Heating load of consumer $n$ at time $t(\mathrm{kWh})$

$P_{n}, Q_{n} \quad$ Apparent power flow of electric load $n(\mathrm{~kW})$

$p_{h, t} \quad$ Pressure of heating node $n$ at time $t(\mathrm{kPa})$

$T w^{i, j} \quad$ Temperature of the wall separating the heating zone $i$ and the heating zone $j\left({ }^{\circ} \mathrm{C}\right)$

Indoor temperature of the heating zone at time $t\left({ }^{\circ} \mathrm{C}\right)$

Bus voltage of node $n$ of the electricity distribution network $(\mathrm{V})$

\section{INTRODUCTION}

Building's share of the global energy consumption is about $40 \%$ [1], with around $50 \%$ of it being consumed for heating or cooling purposes. For example, space heating loads of buildings account for approximately half of the total final energy demand in Europe [2]. Therefore, energy consumption reduction and energy efficiency improvement in buildings, in the heating context, is becoming more prominent. Efficient heating supply solutions for buildings and energy management methods for space heating loads of buildings are of great significance.

The integrated community energy system (ICES) [3] has been extensively used to supply heating for buildings in residential communities. Two main advantages can be achieved: (1) Compared to individual heating solutions, the ICES can meet the heating loads of buildings in a centralized way. Consequently, it saves space and reduces noise emissions in residential communities [4]. (2) With various energy generation and conversion equipment linking various energy systems, the ICES operator can supply heating loads for buildings efficiently and economically.

Moreover, the thermal dynamics of the buildings lead to their thermal inertia [5]. Therefore, indoor temperatures of buildings can be adjusted within a certain range while keeping the consumers' comfort levels [5]. Consequently, consumers in buildings can adjust their heating loads according to the heating sale prices from the ICES operator (i.e., provide heating demand response (HDR)). Therefore, optimal integration and management of heating loads of buildings in the ICES can benefit both the consumers in buildings and the ICES operator.

\section{A. Motivation and related work}

Relevant work has been conducted to study the optimal integration of the heating loads of buildings in integrated energy systems at the transmission level [6]-[9]. The heating loads of buildings are modelled as aggregated thermal storage units at the heat exchangers connected at the transmission level. The results show that aggregated buildings can increase the flexibility of the integrated energy systems thanks to their thermal inertia.

In the above studies, the heating distribution networks are ignored. Actually, the heating distribution networks connect the heating loads of buildings directly, and the buildings' HDR are realized through the heating distribution networks accordingly. In this context, relevant work has been conducted to study the integration and management of the heating loads of buildings in heating distribution systems or integrated electricity/heating distribution systems. Ref. [10] models the flexibility of heating loads of buildings and utilizes the flexibility to manage congestion issues for heating distribution systems. Ref. [11] shows that the buildings' HDR can be used for thermal peak shaving in heating distribution systems. The electric heat boosters' electricity demand response (EDR) was used to provide ancillary services for integrated electricity/heating distribution systems in [12]. However, the buildings' HDR is not adequately considered. Ref. [13] presents an optimal operation approach for the integrated electricity/heating distribution systems, where the heating network and buildings' thermal inertia are considered.

The above studies have made great contributions. However, the heating loads of buildings are considered as inflexible loads, and the buildings' HDR in the optimal dispatch are not well considered. Moreover, the optimal coordination between the consumers in buildings and the operator of the heating distribution system is not adequately considered. Consequently, profits of the operator and energy costs of consumers cannot be balanced. Specifically, the requirements of the optimal coordination lie in two aspects: (1) The consumers in buildings and the operator of the heating distribution system are different entities with conflicting interests, i.e., consumers aim to minimize their costs while the operator seeks to maximize its profit; (2) The operator can optimize heating sale prices to stimulate consumers' HDR, while consumers' heating demand in turn affects the heating prices from the operator. In this case, the benefits of the operator and consumers are correlated with each other in the optimal dispatch. Therefore, the optimal coordination between the operator and the consumers should be considered to balance their benefits.

To address the above issues, a bi-level optimization method for buildings to heating grid integration in the ICES is proposed in [14]. However, uncertainties of distributed renewable generations, energy loads and outdoor environment (e.g., solar radiation and outdoor temperature) are not considered. These uncertainties challenge the optimal dispatch of the ICES with buildings and should be considered accordingly.

\section{B. Contributions of this paper}

To deal with the aforementioned challenges, this paper proposes a bi-level optimization approach for the optimal integration of heating loads of buildings in the ICES. To coordinate the consumers in buildings and the ICES operator in an optimal way, the heating sale prices to consumers in buildings are optimized in the bi-level optimization. The model predictive control (MPC) [15] is further integrated within the bi-level optimization to deal with uncertainties. The main contributions include:

(1) A bi-level optimal integration scheme for consumers in buildings with heating loads in the ICES is proposed. 
Uncertainties of renewable generations, energy prices, and energy loads at the upper level for the ICES operator, and uncertainties of outdoor temperatures and solar radiations at the lower level for consumers in buildings are considered simultaneously.

(2) To achieve economic and reliable scheduling of the ICES and buildings in the presence of uncertainties at both the upper and lower levels, the MPC-based scheduling method is incorporated in the bi-level optimal integration scheme. Moreover, the method to select a proper length of prediction/control horizon for the bi-level MPC problem is developed in this paper. With the proper selection of the length of prediction/control horizon, the obtained MPC solution can balance the benefits of the ICES operator and consumers. This also provides a practical way to select length of prediction/control horizon for other bi-level MPC problems.

(3) To solve the bi-level MPC optimization model efficiently, the original bi-level MPC model is transformed into a MPC based single level mathematical programming with equilibrium constraints problem (MPEC) using the Karush-Kuhn-Tucker (KKT) optimality conditions. Then, the MPC based MPEC is reformulated into a MPC based mixed-integer linear program (MILP) using the strong duality theorem and several linearization techniques.

\section{INTEGRATION OF BUILDINGS IN ICES}

\section{A. Configuration of integration of buildings in ICES}

Fig. 1 illustrates the integration of buildings' heating loads in the ICES. As can be observed, various energy generation and conversion equipment (e.g., heat pump and combined heat and power (CHP) unit) link the electricity distribution network, heating distribution network, and natural gas distribution network together in the ICES. Benefits of the integration of smart buildings in ICES are the following:

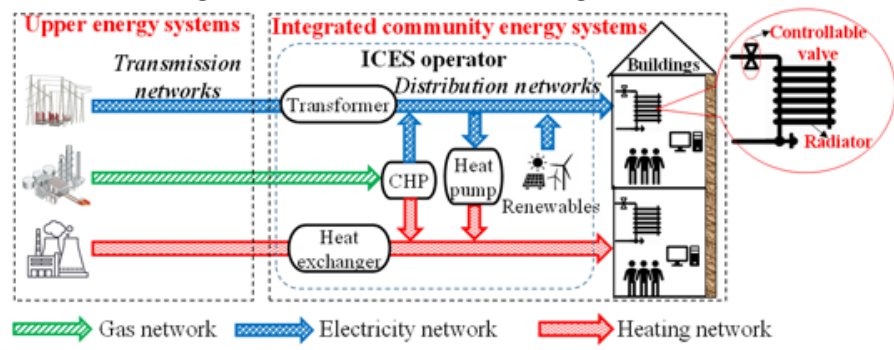

Fig. 1. Schematic diagram of integration of buildings in ICES.

(1) With various energy generation and conversion equipment linking various energy systems, the ICES operator is able to optimize the schedules of energy generation and supply, and the heating sale prices to buildings.

(2) Consumers in buildings are able to provide HDR to the ICES operator according to the heating sale prices from the ICES operator. As shown in Fig. 1, each radiator of each consumer is equipped with a controllable valve. Therefore, consumers in buildings can set preferred comfort temperature ranges on their radiator controllers. The radiator controller can adjust the water flow rate using the controllable valve according to the heating sale prices from the ICES operator. Consequently, the heating cost of the consumer can be reduced while the indoor temperatures are maintained within the comfort range.

(3) There are interactions between the consumers in buildings and the ICES operator. The ICES operator's optimal heating sale prices and consumers' optimal heating loads depend on each other. This calls for a bi-level optimization approach to coordinate the consumers in buildings and the ICES operator.

As shown in Fig. 1, the ICES can supply multi-energy loads of buildings efficiently and economically. The electricity distribution systems can also supply electricity for buildings in communities. Therefore, there are similarities and overlaps in functions and responsibilities of the ICES and the electricity distribution systems in communities. It is also worth noting that there are two main differences between the ICES operator and the electricity distribution system operator (DSO). Firstly, the ICES operator not only manages the electricity distribution system but also manages other energy distribution systems [16], while the electricity DSO only manages the electricity distribution system itself. Secondly, the ICES operator only operates energy distribution systems at the community level. However, the electricity DSO could operate electricity distribution systems at different geographical levels, including the community level, and urban level [17].

\section{B. Bi-level optimal integration of buildings in ICES}

To provide an efficient energy management method for the integration of buildings in the ICES, the following bi-level optimization framework is proposed:

(1) Upper level: In order to maximize the ICES operator's profit, the ICES operator optimizes the energy purchases from upper energy systems (i.e., $P^{e}, P^{h}$, and $P^{g}$ ), schedules of the CHP generation and power consumption of the heat pump, and heating sale prices for buildings.

(2) Lower level: To minimize the heating cost of consumers in buildings, consumers optimize the heating loads $\left(P^{h, L}\right)$ by optimizing the water flow rates in their radiators based on the heating sale prices from the ICES operator.

(3) Interactions: The optimal heating sale prices influence the consumers' heating loads, while the optimal heating loads of consumers in buildings influence the heating sale prices of the ICES operator.

There is a challenge for the optimal integration of buildings in the ICES due to uncertainties. At the upper level, uncertainties of renewable generation, ICES operator's energy purchase prices, and energy loads affect the optimal schedules of energy purchase and generation of the ICES operator, and the optimal heating sale prices. At the lower level, uncertainties of outdoor temperature and solar radiation affect the optimal heating loads of buildings.

There are several methods to handle uncertainties for the optimal integration of buildings in the ICES, e.g., stochastic programming, robust optimization, MPC, etc. The stochastic approaches assume the forecast data follows certain probability density functions. The probability density functions require sufficient historical data, which limits the application of the stochastic method. Since the robust optimization methods are 
based on the worst-case analysis, the obtained solutions are often conservative. MPC can also handle uncertainties since it is a rolling process that runs the optimization model sequentially with updated forecast data while considering the dynamic performance, objectives and constraints of the system. In this perspective, MPC is suitable for optimal scheduling and control of buildings with thermal dynamics and uncertainties of the outdoor environment data (e.g., solar radiation and outdoor temperature), as well as the objectives and constraints. MPC has been widely used for optimal energy management and control of buildings, and the effectiveness have been demonstrated in [15], [18]-[19]. Therefore, MPC is implemented in the bi-level optimization framework for the optimal integration of buildings in the ICES in this paper. The illustration of the MPC based bilevel scheduling is shown in Fig. 2:

At the first time $t=k \& k=1$, the ICES operator and buildings obtain the forecast data over the $N_{p}$ prediction steps $H_{k}^{p}=\left\{k, k+1, \cdots, k+N_{p}-1\right\}$. The forecast data include wind and photovoltaic (PV) generation, ICES operator's energy purchase prices, outdoor temperature and solar radiation. The data is forecasted at each time $t$ and the forecasting granularity is considered as 15 minutes in this paper. Then, the forwardlooking bi-level optimization is solved over the $N_{c}$ control steps $H_{k}^{c}=\left\{k, k+1, \cdots, k+N_{c}-1\right\}$. As highlighted in Fig. 2, only the optimized schedules for the first-time slot at $t$ are applied. Then, at next time $t=k \& k=2$, the ICES operator and buildings get updated forecast data for the next $N_{p}$ time slots and the bi-level optimization problem over the next $N_{c}$ time slots is solved again. The above procedures are repeated until all the control schedules are obtained throughout the day.

\section{FORMULATIONS OF INTEGRATION OF BUILDINGS IN ICES}

\section{A. Formulation of operation of ICES at the upper-level}

\section{1) Objective}

The ICES operator aims to maximize its total benefit over each control horizon $H_{k}^{c}=\left\{k, k+1, \cdots, k+N_{c}-1\right\}, k=1,2, \cdots, n_{h}$. The objective function is as follows:

$$
\begin{aligned}
\max & \sum_{t \in N_{k}^{c}}\left[\sum_{n \in N^{b c}}\left(C e_{t}^{\text {sale }} P_{n, t}^{e, L}+C h_{t}^{\text {sale }} P_{n, t}^{h, L}\right)\right. \\
& +\left(C e_{t}^{\text {sale }} P_{t}^{e, L_{-} O}+C h_{t}^{\text {sale }} P_{t}^{h, L_{-} O}\right) \\
& \left.-\left(C e_{t}^{b u{ }^{\prime} o} P_{t}^{e}+C g_{t}^{b u y \_} P_{t}^{g}+C h_{t}^{b u y \_}{ }^{o} P_{t}^{h}\right)\right]
\end{aligned}
$$

\section{2) Constraints of ICES operator}

- Electricity balance

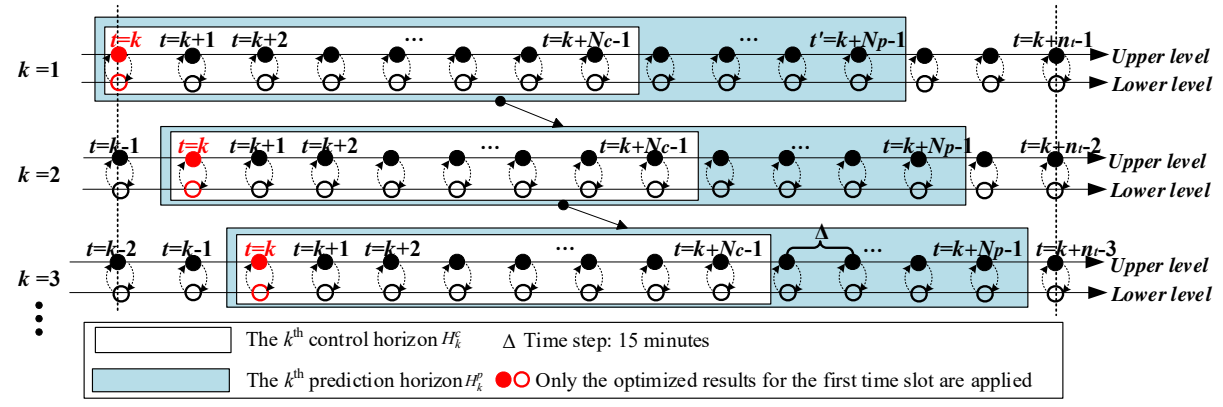

Fig. 2. Illustration of bi-level MPC optimization.

$$
\begin{gathered}
P_{t}^{e}+P_{t}^{c h p}+P_{t}^{P V}+P_{t}^{\text {wind }}= \\
P_{t}^{h p}+\sum_{n \in N^{b c}} P_{n, t}^{e, L}+P_{t}^{e, L_{-} O}+P_{t}^{\text {loss }}, \forall t \in N_{k}^{c} \\
P_{t}^{c h p}=\eta_{e} P_{t}^{g}, \forall t \in N_{k}^{c}
\end{gathered}
$$

Heating balance

$$
\begin{gathered}
H_{t}^{c h p}+H_{t}^{h p}+P_{t}^{h}=\sum_{n \in N^{b c}} P_{n, t}^{h, L}+P_{t}^{h, L_{-} o}, \forall t \in N_{k}^{c} \\
H_{t}^{c h p}=\eta_{h} P_{t}^{g}, \forall t \in N_{k}^{c} \\
H_{t}^{h p}=\eta_{h p} P_{t}^{h p}, \forall t \in N_{k}^{c}
\end{gathered}
$$

The energy purchase from upper energy systems should be limited within certain ranges, as shown in (7)-(9). The constraint of power consumption of the heat pump is shown in (10).

$$
\begin{gathered}
0 \leq P_{t}^{e} \leq \bar{P}_{t}^{e}, \forall t \in N_{k}^{c} \\
0 \leq P_{t}^{g} \leq \bar{P}_{t}^{g}, \forall t \in N_{k}^{c} \\
0 \leq P_{t}^{h} \leq \bar{P}_{t}^{h}, \forall t \in N_{k}^{c} \\
0 \leq P_{t}^{h p} \leq \bar{P}_{t}^{h p}, \forall t \in N_{k}^{c}
\end{gathered}
$$

\section{3) Constraints of heating sale prices}

As shown in (11), to ensure the ICES operator profits, the upper/lower limits of the heating sale price should be set based on the consumers' heating purchase price from the upper energy systems [20]. To ensure consumers' willingness to purchase energy from the ICES operator, (12) is used to limit the average value of the heating sale prices [21].

$$
\begin{gathered}
\alpha_{1} C h_{t}^{b u y_{-} U} \leq C h_{t}^{\text {sale }} \leq \alpha_{2} C h_{t}^{b u y_{-} U}, \forall t \in N_{k}^{c} \\
\sum_{t t \in N_{k}^{c}} C h_{t}^{\text {sale }} / N_{c} \leq \sum_{t \in N_{k}^{c}} C h_{t}^{b u y_{-} U} / N_{c}
\end{gathered}
$$

\section{4) Constraints of heating distribution network}

The heating distribution network connected to buildings is shown in Fig. 3. As can be observed, the controllable valves at radiators can adjust the water flow rates. Then, the heating loads of buildings can be adjusted by consumers to provide HDR to the ICES operator.

The quantity regulation strategy [14], [22] for the heating distribution network (i.e., the constant supply temperature and changing water flow rate) is used in this paper. The rate of water flowing into the pipe node equals the rate of water flowing out of the pipe node [14] [22], as shown in (13). 


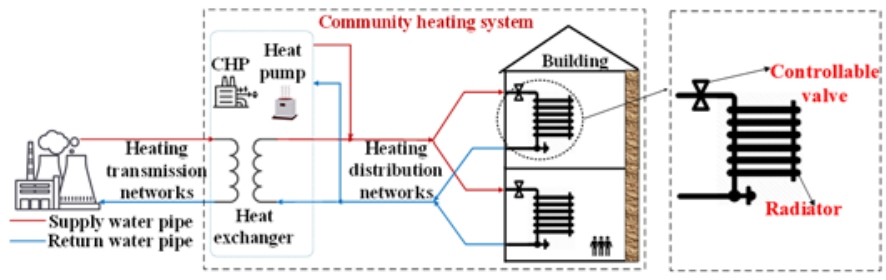

Fig. 3. Schematic diagram of heating distribution network in ICES.

$$
\mathbf{Y}_{H D N} \dot{\mathbf{m}}^{\text {pipe }}=\dot{\mathbf{m}}^{\text {node }}
$$

There are limits of water flow rates in each pipeline, as shown in (14).

$$
\underline{m}_{l}^{p i p e} \leq m_{l, t}^{p i p e} \leq \bar{m}_{l}^{p i p e}, \quad \forall l \in N^{p i p e}, \forall t \in N_{k}^{c}
$$

As shown in (15), the water pressure drops over the pipeline is mainly determined by the water flow rate.

$$
\begin{gathered}
p_{h, t}-p_{h+1, t}=\xi_{l} \cdot\left(m_{l, t}^{\text {pipe }}\right)^{2} \quad \forall l \in N^{\text {pipe }}, h \in N^{\text {node }}, \forall t \in N_{k}^{c} \\
\xi_{l}=\frac{8 \kappa_{l} L_{l}}{d_{l}^{5} \pi^{2} \rho}, \quad \forall l \in N^{\text {pipe }}
\end{gathered}
$$

Limits of pressure of heating node $h$ is shown in (17).

$$
\underline{p}_{h} \leq p_{h, t} \leq \bar{p}_{h}, h \in N^{\text {node }}, \forall t \in N_{k}^{c}
$$

\section{5) Constraints of electricity distribution system}

The radial electricity distribution feeder is shown in Fig. 4. The power flows equations are shown as follows [23].

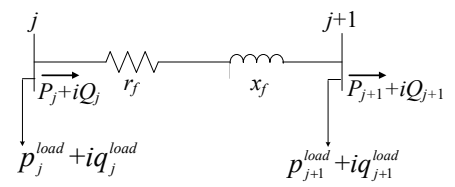

Fig. 4. Example of an electricity distribution feeder.

$$
\begin{gathered}
P_{j+1}=P_{j}-r_{f} \frac{P_{j}^{2}+Q_{j}^{2}}{V_{j}^{2}}-p_{j+1}^{\text {load }} \\
Q_{j+1}=Q_{j}-x_{f} \frac{P_{j}^{2}+Q_{j}^{2}}{V_{j}^{2}}-q_{j+1}^{\text {load }} \\
V_{j+1}^{2}=V_{j}^{2}-2\left(r_{f} P_{j}+x_{f} Q_{j}\right)+\left(r_{f}^{2}+x_{f}^{2}\right) \frac{P_{j}^{2}+Q_{j}^{2}}{V_{j}^{2}}
\end{gathered}
$$

where $j$ is the sending node; $j+1$ is the receiving node; $P_{j}+i Q_{j}$ is the apparent power flow; $V_{j}$ is the voltage of node $j$; $p_{j}^{\text {load }}+i q_{j}^{\text {load }}$ is the apparent power load of node $j ; r_{f}+i x_{f}$ is the impedance of the electricity branch from node $j$ to $j+1$. The perunit voltage should be within the bounds, as shown in (21) [23].

$$
1-\varepsilon \leq V_{j} \leq 1+\varepsilon
$$

\section{B. Formulation of decision making of consumers in buildings} at lower-level

\section{1) Objective}

The decision-making objective of the consumer in buildings is to minimize its total cost over each control horizon $H_{k}^{c}=\left\{k, k+1, \cdots, k+N_{c}-1\right\}, k=1,2, \cdots, n_{h}$ based on the heating sale prices from the ICES operator. The objective function of consumer $n$ is shown in (22).

$$
\min \sum_{t \in N_{k}^{c}}\left(C e_{t}^{\text {sale }} P_{n, t}^{e, L}+C h_{t}^{\text {sale }} P_{n, t}^{h, L}\right), n \in N^{b c}
$$

\section{2) Constraints}

Constraints of thermal balance of each consumer

The thermal dynamics of heating loads in each heating zone of each consumer is modeled using the Resistor-Capacitor (RC) thermal network model [5], [14], [24]. The thermal dynamics of the heating zone include the thermal balance of the indoor air in the heating zone and the thermal balance of walls [14]. Taking heating zone 1 as an example, its RC model is shown in Fig. 5. As can be observed, two different kinds of nodes (i.e., the wall and heating zone nodes) are considered in the RC model of the heating zone. The nodes are linked with each other through thermal resistance representing the ability to transmit heat, and grounded by thermal capacity representing the ability to preserve heat [5], [14], [24]. As shown in Fig. 5, there are four wall nodes in the surrounding walls identified by number 2 5 (highlighted in blue) and one heating zone node identified by number 1 (highlighted in red) in heating zone 1 . The RC thermal network model is also utilized in [5], [14], [24], and its accuracy is demonstrated on a testbed room in the campus of UC Berkeley [25]. Since the RC model is not the focus of this paper, the comparisons between the actual indoor temperature measurements and the forecasted indoor temperatures using the $\mathrm{RC}$ model are not presented in this paper.

The relationship among the outdoor temperature, heat gains of the heating zone, and the wall temperatures can be formulated using the RC model with the wall and heating zone nodes. Then, the thermal balance of the walls of heating zone 1 is formulated as,

$$
\left\{\begin{array}{l}
C w^{1,2} \frac{d T w^{1,2}}{d t}=\frac{T^{r o o m}-T w^{1,2}}{R w^{1,2}}+\frac{T^{2}-T w^{1,2}}{R w^{1,2}}+r^{1,2} \alpha^{1,2} A w^{1,2} \operatorname{Rrad}^{1,2} \\
C w^{1,3} \frac{d T w^{1,3}}{d t}=\frac{T^{r o o m}-T w^{1,3}}{R w^{1,3}}+\frac{T^{3}-T w^{1,3}}{R w^{1,3}}+r^{1,3} \alpha^{1,3} A w^{1,3} \mathrm{Qrad}^{1,3} \\
C w^{1,4} \frac{d T w^{1,4}}{d t}=\frac{T^{r o o m}-T w^{1,4}}{R w^{1,4}}+\frac{T^{4}-T w^{1,4}}{R w^{1,4}}+r^{1,4} \alpha^{1,4} A w^{1,4} \mathrm{Qrad}^{1,4} \\
C w^{1,5} \frac{d T w^{1,5}}{d t}=\frac{T^{r o o m}-T w^{1,5}}{R w^{1,5}}+\frac{T^{5}-T w^{1,5}}{R w^{1,5}}+r^{1,5} \alpha^{1,5} A w^{1,5} \mathrm{Qrad}^{1,5}
\end{array}\right.
$$

where $T w^{12}, T w^{13}, T w^{14}$, and $T w^{15}$ are temperatures of the four wall nodes that represent the temperatures of the surrounding walls of heating zone 1 ; $T^{\text {room }}$ is the temperature of the heating zone node that represents the indoor temperature of heating zone $1 ; T^{2} \sim T^{5}$ are temperatures of adjacent heating zones when there are adjacent heating zones; otherwise, they are outdoor temperatures. Taking heating zone 1 as an example, $T^{2}$ and $T^{3}$ are outdoor temperatures, and $T^{4}$ and $T^{5}$ are temperatures of adjacent heating zones of heating zone 1 .

Similarly, the thermal balance of the heating zone's indoor air can be formulated as,

$$
\begin{aligned}
C r \frac{d T^{\text {room }}}{d t}= & \sum_{j=2}^{5} \frac{T w^{1, j}-T^{\text {room }}}{R w^{1, j}}+\frac{T^{\text {out }}-T^{\text {room }}}{R \text { win }} \\
& +Q_{1}^{\text {load }}+Q^{\text {int }}+\tau^{\text {win }} A^{\text {win }} Q^{\text {win }}
\end{aligned}
$$




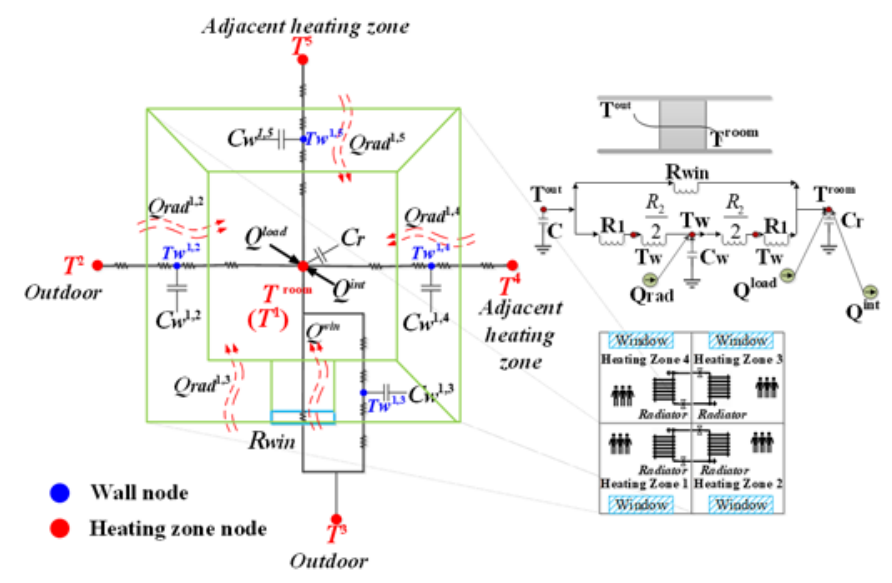

Fig. 5. RC model of one heating zone of one consumer.

The thermal dynamics of buildings are differential equations (see (23) and (24)), which are difficult to be solved in the optimization model [26]. Therefore, the differential equations are transformed into discrete difference equations, as shown in (25) and (26).

$$
\left\{\begin{aligned}
& C w^{1,2} T w_{t+1}^{1,2}=\left(C w^{1,2}-\frac{2 \Delta t}{R w^{1,2}}\right) T w_{t}^{1,2} \\
&+\left(r^{1,2} \alpha^{1,2} A w^{1,2} Q r a d^{1,2}\right) \Delta t+\frac{\left(T_{t}^{\text {room }}+T_{t}^{2}\right) \Delta t}{R w^{1,2}}: \lambda_{1, t} \\
& C w^{1,3} T w_{t+1}^{1,3}=\left(C w^{1,3}-\frac{2 \Delta t}{R w^{1,3}}\right) T w_{t}^{1,3} \\
&+\left(r^{1,3} \alpha^{1,3} A w^{1,3} Q r a d^{1,3}\right) \Delta t+\frac{\left(T_{t}^{\text {room }}+T_{t}^{3}\right) \Delta t}{R w^{1,3}}: \lambda_{2, t} \\
& C w^{1,4} T w_{t+1}^{1,4}=\left(C w^{1,4}-\frac{2 \Delta t}{R w^{1,4}}\right) T w_{t}^{1,4} \\
&+\left(r^{1,4} \alpha^{1,4} A w^{1,4} Q r a d^{1,4}\right) \Delta t+\frac{\left(T_{t}^{\text {room }}+T_{t}^{4}\right) \Delta t}{R w^{1,4}}: \lambda_{3, t} \\
& C w^{1,5} T w_{t+1}^{1,5}=\left(C w^{1,5}-\frac{2 \Delta t}{R w^{1,5}}\right) T w_{t}^{1,5} \\
&+\left(r^{1,5} \alpha^{1,5} A w^{1,5} \operatorname{Qrad} d^{1,5}\right) \Delta t+\frac{\left(T_{t}^{\text {room }}+T_{t}^{5}\right) \Delta t}{R w^{1,5}}: \lambda_{4, t} \\
& \operatorname{Cr}\left(T_{t+1}^{\text {room }}-T_{t}^{\text {room }}\right)=\Delta t\left(\sum_{j=2}^{5} \frac{T w_{t}^{1, j}-T_{t}^{\text {room }}}{R w^{1, j}}+\frac{T_{t}^{\text {out }}-T_{t}^{\text {room }}}{R w i n}\right. \\
&\left.\quad+Q_{i, t}^{\text {lood }}+Q_{t}^{\text {int }}+\tau^{\text {win }} A^{\text {win }} Q_{t}^{\text {win }}\right): \lambda_{5, t}
\end{aligned}\right.
$$

where $\Delta t$ is the time interval; $\lambda_{1, t}, \lambda_{2, t}, \lambda_{3, t}, \lambda_{4, t}$, and $\lambda_{5, t}$ are dual variables of the difference equations (25) and (26).

As shown in (27), the heating load of the heating zone $i\left(Q_{i}^{\text {load }}\right)$ is met through the heating exchange through the radiator. Then, the total heating load of the consumer with $I$ heating zones is obtained by (28).

$$
\begin{aligned}
Q_{i, t}^{\text {load }} & =c_{p} * m_{t}^{r} *\left(T_{s}-T_{r}\right) \\
P_{1, t}^{h, L} & =\sum_{i=1}^{I} Q_{i, t}^{\text {load }}, \forall t \in N_{k}^{c}
\end{aligned}
$$

- Constraints of indoor temperatures

$$
\underline{T}_{t}^{\text {room }} \leq T_{t}^{\text {room }} \leq \bar{T}_{t}^{\text {room }}, t \in N_{k}^{c}: \beta_{1}^{L}, \beta_{1}^{U}
$$

- Limits of water flow rates of radiators

$$
\underline{m}_{t}^{r} \leq m_{t}^{r} \leq \bar{m}_{t}^{r}, t \in N_{k}^{c}: \beta_{2}^{L}, \beta_{2}^{U}
$$

where $\beta_{1}^{L}, \beta_{1}^{U}, \beta_{2}^{L}, \beta_{2}^{U}$ are dual variables.

As can be observed from the formulations of the proposed bilevel method, the heating sale prices generated by the upperlevel model (see (1)) guide the heating loads in the lower-level model, while the optimal heating loads generated by the lowerlevel model (see (22)) in turn affect the heating sale prices of the ICES operator in the upper-level model. Therefore, in the proposed bi-level method, the ICES operator and the customers determine the optimal heating sale prices together through the bi-level optimization.

\section{Solution Method}

\section{A. Reformulate the bi-level optimization}

Since the heating sale prices are determined by the upperlevel optimization, they can be considered as constants in the lower-level problem. Consequently, the lower-level problem is continuous and convex, and it is equivalent to its KKT optimality conditions [27]. Then, the bi-level optimization problem can be reformulated as a single-level mathematical problem with complementarity constraints (MPEC) [27]. The KKT optimality conditions are shown in (31)-(36).

$$
\begin{aligned}
& \text { - Lagrange function } \\
& L\left(T_{t}^{\text {room }}, T w_{t}^{1,2}, T w_{t}^{1,3}, T w_{t}^{1,4}, T w_{t}^{1,5}, m_{t}^{r}\right)= \\
& \sum_{t \in N_{k}^{c}}\left(C e_{t}^{\text {sale }} P_{n, t}^{e, L}+C h_{t}^{\text {sale }} P_{n, t}^{h, L}\right)-\sum_{j \in \Omega_{\text {inequal }}} \beta_{i} h_{j}+\sum_{k \in \Omega_{\text {equal }}} \lambda_{k} g_{k} \\
& \text { Stationarity conditions } \\
& \frac{\partial L}{\partial T_{t}^{\text {room }}}=\frac{\lambda_{1, t} \Delta t}{R w^{1,2}}+\frac{\lambda_{2, t} \Delta t}{R w^{1,3}}+\frac{\lambda_{3, t} \Delta t}{R w^{1,4}}+\frac{\lambda_{4, t} \Delta t}{R w^{1,5}} \\
& +\left(C r-\frac{\Delta t}{R w i n}-\left(\Delta t * \sum_{j=2}^{5} \frac{1}{R w^{1, j}}\right)\right) \lambda_{5, t} \\
& -C r^{*} \lambda_{5, t-1}-\beta_{1, t}^{L}+\beta_{1, t}^{U}=0, t \in N_{k}^{c} \\
& \int \frac{\partial L}{\partial T w_{t}^{1,2}}=\left(C w^{1,2}-\frac{2 \Delta t}{R w^{1,2}}\right) \lambda_{1, t}+\frac{\lambda_{5, t} \Delta t}{R w^{1,2}}-C w^{1,2} \lambda_{1, t-1}=0, t \in N_{k}^{c} \\
& \left\{\frac{\partial L}{\partial T w_{t}^{1,3}}=\left(C w^{1,3}-\frac{2 \Delta t}{R w^{1,3}}\right) \lambda_{2, t}+\frac{\lambda_{5, t} \Delta t}{R w^{1,3}}-C w^{1,3} \lambda_{2, t-1}=0, t \in N_{k}^{c}\right. \\
& \frac{\partial L}{\partial T w_{t}^{1,4}}=\left(C w^{1,4}-\frac{2 \Delta t}{R w^{1,4}}\right) \lambda_{3, t}+\frac{\lambda_{5, t} \Delta t}{R w^{1,4}}-C w^{1,4} \lambda_{3, t-1}=0, t \in N_{k}^{c} \\
& \frac{\partial L}{\partial T w_{t}^{1,5}}=\left(C w^{1,5}-\frac{2 \Delta t}{R w^{1,5}}\right) \lambda_{4, t}+\frac{\lambda_{5, t} \Delta t}{R w^{1,5}}-C w^{1,5} \lambda_{4, t-1}=0, t \in N_{k}^{c} \\
& \frac{\partial L}{\partial m_{t}^{r}}=C h_{t}^{\text {sale }} *\left(c_{p} *\left(T_{s}-T_{r}\right) * I\right)+\lambda_{5, t} *\left(c_{p} *\left(T_{s}-T_{r}\right)\right) \\
& -\beta_{2, t}^{L}+\beta_{2, t}^{U}=0, t \in N_{k}^{c}
\end{aligned}
$$

Complementary slackness conditions

$$
\begin{gathered}
\left\{\begin{array}{l}
0 \leq \beta_{1, t}^{L} \perp\left(T_{t}^{\text {room }}-\underline{T}_{t}^{\text {room }}\right) \geq 0, t \in N_{k}^{c} \\
0 \leq \beta_{1, t}^{U} \perp\left(\bar{T}_{t}^{\text {room }}-T_{t}^{\text {room }}\right) \geq 0, t \in N_{k}^{c}
\end{array}\right. \\
\left\{\begin{array}{l}
0 \leq \beta_{2, t}^{L} \perp\left(m_{t}^{r}-\underline{m}_{t}^{r}\right) \geq 0, t \in N_{k}^{c} \\
0 \leq \beta_{2, t}^{U} \perp\left(\bar{m}_{t}^{r}-m_{t}^{r}\right) \geq 0, t \in N_{k}^{c}
\end{array}\right.
\end{gathered}
$$

\section{B. Linearization of the complementarity constraints}

The bilinear term $C h_{t}^{\text {sale }} P_{n, t}^{e, L}$ in (1) and the complementary 
slackness conditions in (35)-(36) make the MPEC model nonlinear. The complementary slackness conditions are transformed to a linear form using the Big-M method [28]. Then, Eqs. (35)-(36) can be linearized and replaced by (37)-(44) by introducing auxiliary binary variables.

$$
\begin{gathered}
0 \leq \beta_{1, t}^{L} \leq M \theta_{1, t}^{L}, t \in N_{k}^{c} \\
0 \leq T_{t}^{\text {room }}-\underline{T}^{\text {room }} \leq M\left(1-\theta_{1, t}^{L}\right), t \in N_{k}^{c} \\
0 \leq \beta_{1, t}^{U} \leq M \theta_{1, t}^{U}, t \in N_{k}^{c} \\
0 \leq \bar{T}_{t}^{\text {room }}-T_{t}^{\text {room }} \leq M\left(1-\theta_{1, t}^{U}\right), t \in N_{k}^{c} \\
0 \leq \beta_{2, t}^{L} \leq M \theta_{2, t}^{L}, t \in N_{k}^{c} \\
0 \leq m_{t}^{r}-\underline{m}_{t}^{r} \leq M\left(1-\theta_{2, t}^{L}\right), t \in N_{k}^{c} \\
0 \leq \beta_{2, t}^{U} \leq M \theta_{2, t}^{U}, t \in N_{k}^{c} \\
0 \leq \bar{m}_{t}^{r}-m_{t}^{r} \leq M\left(1-\theta_{2, t}^{U}\right), t \in N_{k}^{c}
\end{gathered}
$$

where $M$ is a big enough constant number; $\theta_{1, t}^{L}, \theta_{1, t}^{U}, \theta_{2, t}^{L}, \theta_{2, t}^{U}$ are auxiliary binary variables.

\section{Linearization of the bilinear term}

$$
\begin{aligned}
& \text { Dual_inner } r_{1, t}=\underbrace{\sum_{t \in N_{t}^{c}}\left(C e_{t}^{\text {sale }} P_{1, t}^{e, L}+C h_{t}^{\text {sale }} P_{1, t}^{h, L}\right)}_{\text {primal }} \\
& =\left(\begin{array}{l}
\sum_{t=1}^{T} C e_{t}^{\text {sale }} P_{1, t}^{e, L}-\sum_{t=1}^{T} \beta_{2, t}^{U} \bar{m}_{t}^{r}+\sum_{t=1}^{T} \beta_{1, t}^{L} T_{t}^{\text {room }} \\
-\sum_{t=1}^{T} \beta_{1, t}^{U} \bar{T}_{t}^{\text {room }}+\sum_{t=1}^{T}\left(-\frac{T_{t}^{2}}{R w^{1,2}} \lambda_{1, t}\right) \\
+\sum_{t=1}^{T}\left(-r^{1,2} \alpha^{1,2} A w^{1,2} Q r a d^{1,2} \lambda_{1, t}\right)+\sum_{t=1}^{T}\left(-\frac{T_{t}^{3}}{R w^{1,3}} \lambda_{2, t}\right) \\
+\sum_{t=1}^{T}\left(-r^{1,3} \alpha^{1,3} A w^{1,3} Q r a d^{1,3} \lambda_{2, t}\right)+\sum_{t=1}^{T}\left(-\frac{T_{t}^{4}}{R w^{1,4}} \lambda_{3, t}\right) \\
+\sum_{t=1}^{T}\left(-r^{1,4} \alpha^{1,4} A w^{1,4} Q r a d^{1,4} \lambda_{3, t}\right)+\sum_{t=1}^{T}\left(-\frac{T_{t}^{5}}{R w^{1,5}} \lambda_{4, t}\right) \\
+\sum_{t=1}^{T}\left(-r^{1,5} \alpha^{1,5} A w^{1,5} \operatorname{Rrad}^{1,5} \lambda_{4, t}\right)+\sum_{t=1}^{T}\left(-\frac{T_{t}^{\text {out }}}{R w i n} \lambda_{5, t}\right) \\
+\sum_{t=1}^{T}\left(-Q_{t}^{\text {int }} \lambda_{5, t}\right)+\sum_{t=1}^{T}\left(-\tau^{\text {win }} A^{\text {win }} Q_{t}^{\text {win }} \lambda_{5, t}\right)
\end{array}\right. \\
& \text { dual }
\end{aligned}
$$

,$n \in N^{b c}$

The bilinear term $C h_{t}^{\text {sale }} P_{n, t}^{e, L}$ in (1) can be linearized according to the strong duality theorem [27]. According to the strong duality theorem [27], the optimal objective of the primal problem is equal to the optimal objective of its corresponding dual problem as long as the problem is convex. Since the lowerlevel problem is linear and convex, it satisfies the strong duality theorem. Hence, the optimal objective of the primal problem of the lower-level problem (i.e., Eq. (22)) equals to the optimal objective of its dual problem, as shown in (45).

Based on (45), the nonlinear part (i.e., $C h_{t}^{\text {sale }} P_{n, t}^{h, L}+C e_{t}^{\text {sale }} P_{n, t}^{e, L}$ ) in (1) can be replaced by the term Dual_inner ${ }_{n, t}$, as shown in (46). The term Dual_inner ${ }_{n, t}$ is linear. Accordingly, the updated objective in (46) is linear.

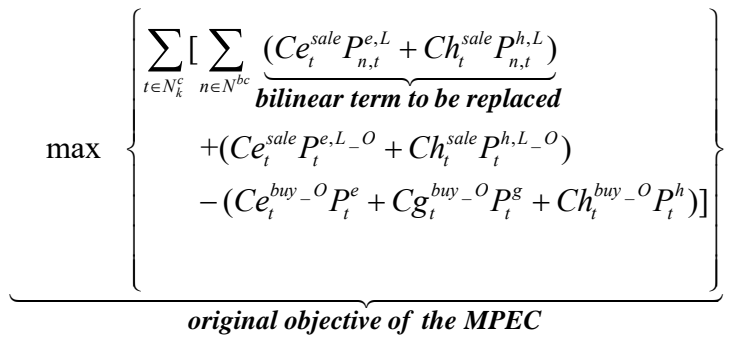

$$
\begin{aligned}
& =\underbrace{\max \left\{\begin{array}{c}
\sum_{t \in N_{k}^{c}}[\sum_{n \in N^{b c}} \underbrace{\left(\text { Dual_inner }_{n, t}\right)}_{\text {linear term replaced }} \\
+\left(C e_{t}^{\text {sale }} P_{t}^{e, L_{-} O}+C h_{t}^{\text {sale }} P_{t}^{h, L_{-} o}\right) \\
\left.-\left(C e_{t}^{b u y}{ }^{o} P_{t}^{e}+C g_{t}^{b u y}{ }^{o} P_{t}^{g}+C h_{t}^{b u{ }_{-} o} P_{t}^{h}\right)\right]
\end{array}\right\}}_{\text {updated objective of the MPEC }}
\end{aligned}
$$

D. Linearization of the constraints of electricity and heating distribution systems

Eqs. (15) and (18)-(20) are nonlinear, which need to be linearized. The piecewise linear function [29] is utilized to approximate the nonlinear function in (15). Therefore, the flow rate of pipeline $l$, i.e., $m_{l, t}^{p i p e}$ in (15), is divided into $Q$ segments ( $q \in Q$ ) in $\left[\underline{m}_{l}^{p i p e}, \bar{m}_{l}^{p i p e}\right]$ as abscissas. The corresponding ordinates and slopes are calculated by (47)-(48).

$$
\begin{gathered}
y_{l}^{q}=0, \quad x_{l}^{q}=0 \quad q=1 \\
y_{l}^{q}=\left(x_{l}^{q}\right)^{2}, \quad x_{l}^{q}=\frac{\bar{m}_{l}^{p i p e} \cdot q}{Q}, \quad k_{l}^{q}=\frac{y_{l}^{q}-y_{l}^{q-1}}{x_{l}^{q}-x_{l}^{q-1}} \quad q \geq 2
\end{gathered}
$$

As shown in (49), by decomposing the curve of the nonlinear function in (15) into several segments, it can be approximated by several linear functions. The constraints of the piecewise linear segments are shown in (50)-(51):

$$
\begin{gathered}
p_{h, t}-p_{h+1, t}=\xi_{l} \cdot \sum_{q=1}^{Q}\left[\left(A_{l, t}^{p i p e}-x_{l}^{q} \delta_{l, t}^{q}\right) k_{l}^{q}+y_{l}^{q} \delta_{l, t}^{q}\right] \\
\delta_{l, t}^{q} x_{l}^{q} \leq A_{l, t}^{p i p e} \leq \delta_{l, t}^{q} x_{l}^{q+1} \\
\sum_{q=1}^{Q} \delta_{l, t}^{q}=1
\end{gathered}
$$

where $A_{l, t}^{p i p e}$ equals $m_{l, t}^{p i p e} ; \delta_{l, t}^{q}$ is the auxiliary binary variable, which represents whether the value of $A_{l, t}^{p i p e}$ is in the abscissas of $q$.

The power flow equations, i.e. (18)-(20), can be linearized through two assumptions [23]: (1) The nonlinear terms $\left(\frac{P_{j}^{2}+Q_{j}^{2}}{V_{j}^{2}}\right)$ which represents losses is much smaller than the branch power terms in practice [23]; (2) $\left(V_{j}-V_{0}\right)^{2} \approx 0$, which leads to $V_{j}^{2} \approx$ $V_{0}^{2}+2 V_{0}\left(V_{j}-V_{0}\right)$ [23]. After the linearization, the constraints of the distribution network are shown in (52)-(54).

$$
\begin{gathered}
P_{j+1}=P_{j}-p_{j+1}^{\text {load }} \\
Q_{j+1}=Q_{j}-q_{j+1}^{\text {load }} \\
V_{j+1}=V_{j}-\frac{r_{f} P_{j}+x_{f} Q_{j}}{V_{0}}
\end{gathered}
$$

After the linearization introduced above, the objective 
function of the upper-level model and all the constraints are linear. Therefore, the final MPEC model is a MILP model. Finally, the optimal integration of buildings in ICES is an MPC based MILP model, as shown in (55). At each control horizon, the MILP model in (55) is solved until all the control schedules are obtained throughout the day.

obj. (46)

$$
\begin{array}{ll}
\text { s.t. } & \text { (2)-(14), (16)-(17), (21), (23)-(34), (37)-(44), } \\
& \text { and (47)-(54), } \forall t \in N_{k}^{c}, n \in N^{b c}
\end{array}
$$

\section{E. Implementation of the bi-level MPC approach}

After transforming the bi-level optimization model into a single-level MILP model. The MPC on the MILP model can be implemented with the following five steps:

Step 1: At the first scheduling time $t=k \& k=1$, the ICES operator and buildings obtain the forecast data over the $N_{p}$ prediction steps $H_{k}^{p}=\left\{k, k+1, \cdots, k+N_{p}-1\right\}$.

Step 2: Obtain the optimal schedules by solving the MILP model in (55) over the $N_{c}$ control steps $H_{k}^{c}=\left\{k, k+1, \cdots, k+N_{c}-1\right\}$. The optimal schedules for the ICES operator include schedules of energy generation and supply, and the heating sale prices. The optimal schedules for consumers in buildings are their optimal heating loads (i.e., schedules of water flow rates of consumers' radiators and their indoor temperatures).

Step 3: Apply the optimal schedules for the first-time slot at $t$ obtained in Step 2. Then the optimal schedules for the ICES operator and the buildings at scheduling time $t$ are obtained.

Step 4: The time slot moves forward by one time slot for next optimization. At next scheduling time $t=k \& k=2$, the ICES operator and buildings get updated forecast data for the next $N_{p}$ time slots.

Step 5: Implement Step 2 again until all the optimal schedules for the ICES operator and the buildings are obtained.

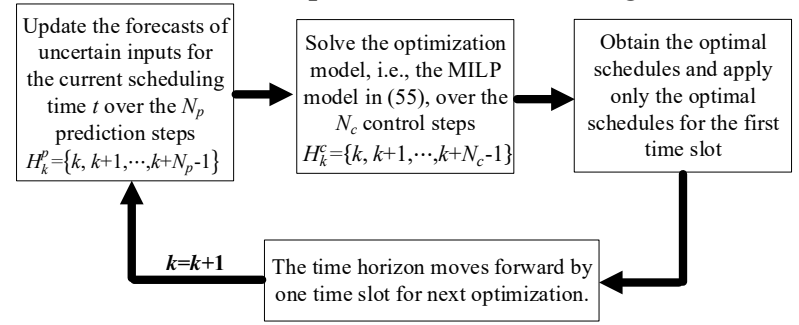

Fig. 6. Rolling process of the MPC.

The implementation of MPC is a rolling process that runs the optimization model (i.e., the MILP model in (55)) repeatedly with updated forecasts. The rolling process is illustrated in Fig. 6 . The optimization for each time slot in the rolling process is based on the latest forecast data and the forecast data is updated repeatedly in the next time slot. Therefore, this rolling process can handle the uncertainties of the forecast data. The ability of MPC's rolling process to handle uncertainties is also reported in [30]-[31].

\section{CASE Study}

Several cases are presented in this section to demonstrate the performance of the proposed bi-level MPC method. The base case demonstrates the basic characteristics of the proposed bilevel MPC method, while the case with forecast errors demonstrates the advantages of the MPC method for economic scheduling of the ICES and buildings in the presence of uncertainties.

A. Base case

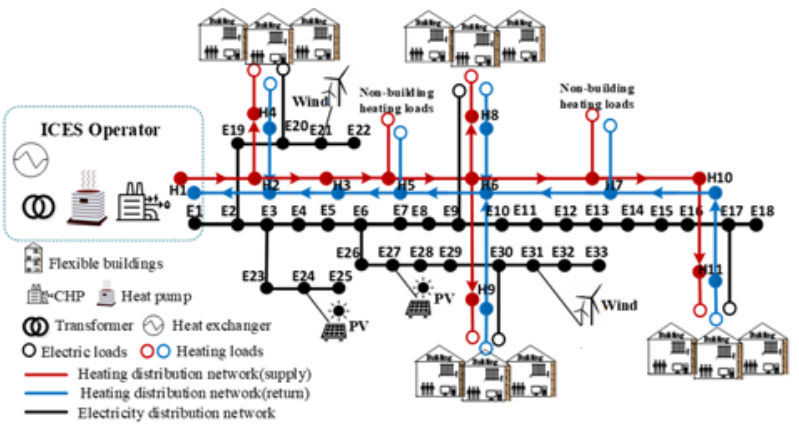

Fig. 7. Schematic of the ICES with buildings.

The integrated heating/electricity community energy systems with buildings are used as a test case, as shown in Fig. 7. Two PV units are connected to nodes 24 and 27; two wind generation units are connected to nodes 21 and 31 . The PV and wind units are assumed to be owned by the ICES operator. The capacities of the PV generation units and wind generation units are assumed as 300 and $500 \mathrm{~kW}$. The wind and PV generation data throughout the day are from [1], as shown in Fig. 8. It is assumed that there are four heating zones in each consumer, and each zone is $3 \mathrm{~m}$ high, $6 \mathrm{~m}$ wide, and $6 \mathrm{~m}$ long. There are 20 floors in each building and two consumers at each floor. The number of buildings connected to the ICES and the connection locations are summarized in TABLE I. Heating nodes $\mathrm{H} 4, \mathrm{H} 8$, $\mathrm{H} 9$, and $\mathrm{H} 11$ connect building heating loads, while $\mathrm{H} 5$ and $\mathrm{H}$ 7 connect non-building heating loads without heating demand response (i.e., non-flexible heating loads). Electricity nodes $\mathrm{E}$ 20, E 9, E 30, and E 17 connect building electricity loads, and other electricity nodes connect non-building electricity loads. Since the EDR from buildings is out of scope of this paper, the total electricity loads of all consumers in a typical winter day of northern China are used [32], which is shown in Fig. 9. The parameters of one heating zone are shown in TABLE II [5] [14]. Other parameters are summarized in TABLE III. The data of the outdoor environment (i.e., solar radiation and outdoor temperature) are from [5]. The energy purchase prices for the ICES operator and the consumers are shown in Fig. 10. In the base case, the forecast data are considered accurate. The time interval $\Delta t$ is set as 15 minutes. The prediction and control horizon are set as $10 \mathrm{~h}$ in this paper, i.e., $N_{p}=N_{c}=40$. Therefore, there are 40 time slots for each prediction or control horizon.

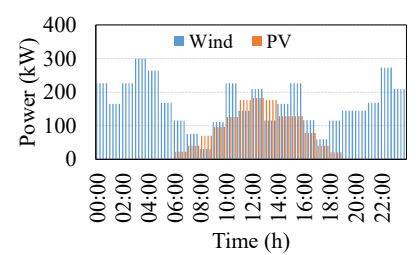

Fig. 8. Renewable generation.

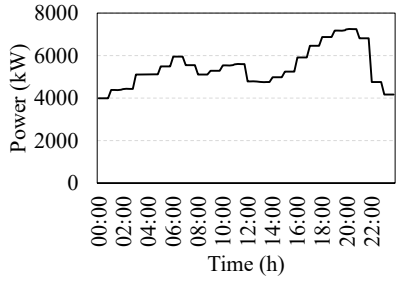

Fig. 9. Total electricity loads of consumers in the ICES. 
TABLE I CONNECTED BUILDINGS IN THE ICES

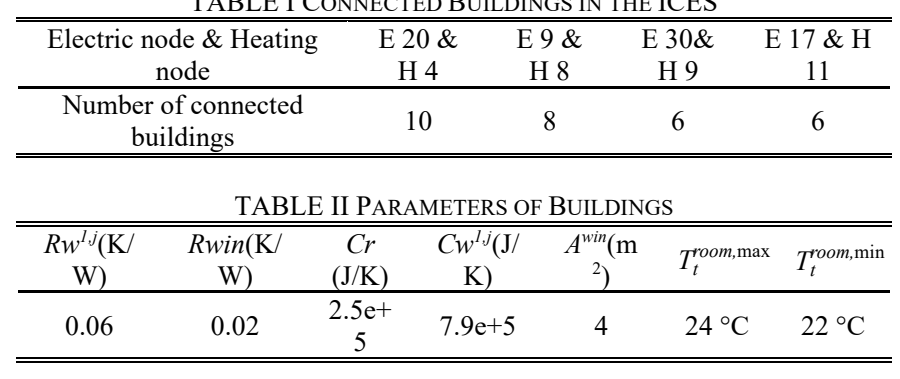

TABLE III OTHER PARAMETERS

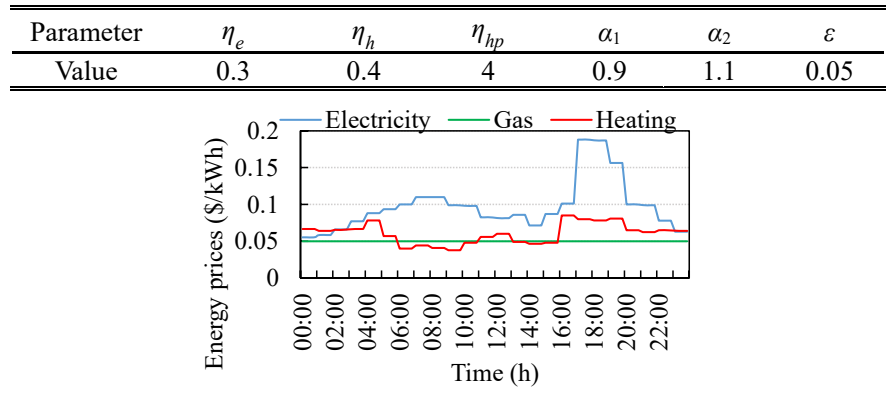

(a) Operator's energy purchase prices.

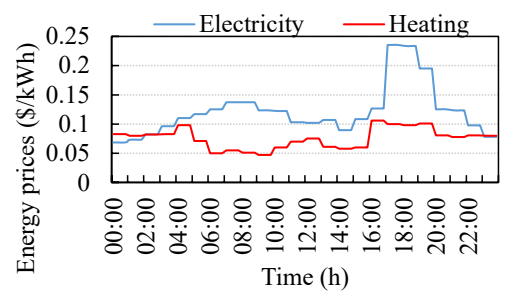

(b) Consumers' energy purchase prices

Fig. 10. Energy purchase prices from the upper energy systems.

\section{1) Base scheduling results}

As shown in Fig. 11 (a), the ICES operator can optimize its energy purchases from upper electricity, natural gas, and heating systems according to energy purchase prices. As shown in Fig. 11 (b), since the efficiency of the heating generation of the CHP is lower than that of the heat pump, the ICES operator dispatches the heat pump for heating supply in most of the time slots throughout the day. Due to the limit of the heating generation capacity of the heat pump, the ICES operator needs to purchase heating from upper systems directly (e.g., at 00:15, 08:00, 22:15, etc.) or dispatch CHP (e.g., 05:00, 17:00 20:00, $21: 15$, etc.) for heating supply when heating loads peak at some time slots. The choices between heating purchases and CHP dispatching by using natural gas are determined according to the operator's energy purchase prices (see Fig. 10 (a) and Fig. 11 (a)). As can be observed from Fig. 11 (c), heating sale prices are optimized within the range.

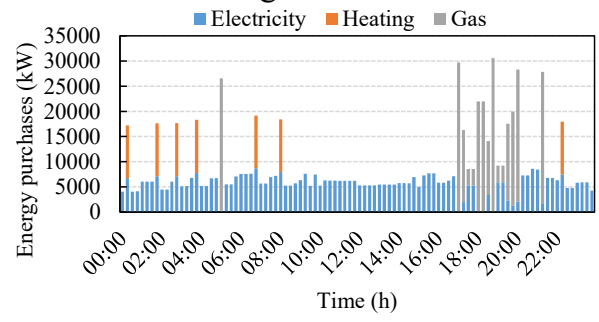

(a) Schedules of energy purchases.

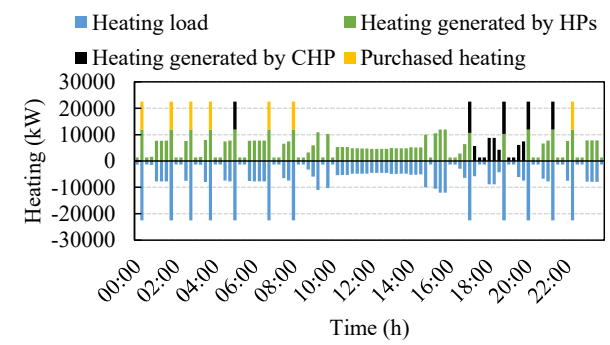

(b) Heating supply schedules.

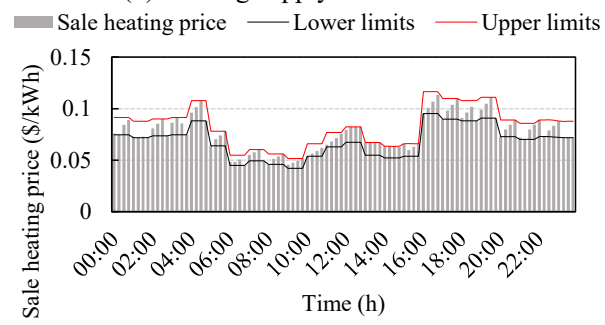

(c) Optimal heating sale prices.

Fig. 11. Scheduling results of ICES operator.

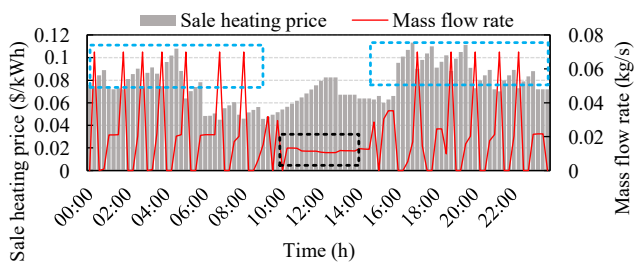

(a) Optimal water flow rate in the radiator.

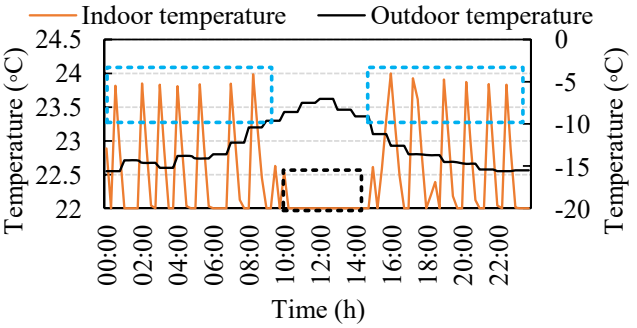

(b) Optimal indoor temperature.

Fig. 12. Scheduling results of one heating zone of one consumer.

As can be observed from the circled areas with blue lines in Fig. 12 (a), the water flow rates change frequently due to frequently changing heating sale prices. Specifically, peaks of heating sale prices cause the valleys of the water flow rates. By contrast, the valleys of heating sale prices cause the peaks of the water flow rates. Frequent changes in the flow rates lead to frequent changes in indoor temperatures consequently, as shown in the circled areas with blue lines from 00:00 to 09:00, and from 15:00 to 23:00 in Fig. 12 (b). As shown in the circled areas with black lines from 10:00 to 14:00 in Fig. 12 (a) (b), the heating sale prices change little over time. Consequently, the flow rates and indoor temperatures change little.

The length of prediction/control horizon of the bi-level MPC problem affects the optimization results. The optimization results are obtained with different prediction/control horizons from $1 \mathrm{~h}$ to $23 \mathrm{~h}$. As highlighted in Fig. 13, compared with other solutions, the optimization results with $10 \mathrm{~h}$ prediction/control horizon (i.e., $N_{p}=N_{c}=40$ ) can obtain a solution with a relative balance of the benefits of consumers and the ICES operator. Therefore, the prediction/control horizon is set as $10 \mathrm{~h}$. 


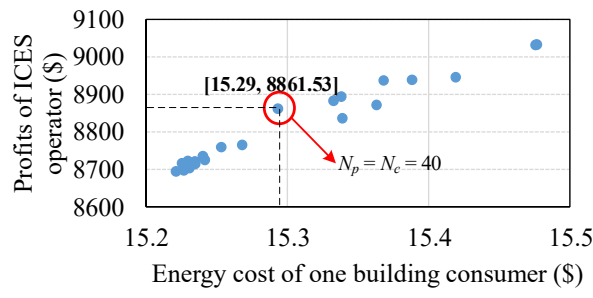

Fig. 13. MPC optimization results with different prediction/control horizons.

\section{2) Benefits analysis through comparative studies}

Three scenarios are carried out for the benefits analysis, as shown in TABLE IV.

TABLE IV THREE COMPARATIVE SCENARIOS

\begin{tabular}{|c|c|c|c|}
\hline Scenario & Heating sale price & $\begin{array}{c}\text { Consumers } \\
\text { participate } \\
\text { in sale } \\
\text { heating } \\
\text { pricing } \\
\end{array}$ & $\begin{array}{c}\text { Consumers } \\
\text { provide } \\
\text { HDR }\end{array}$ \\
\hline I & Optimized & $\sqrt{ }$ & $\sqrt{ }$ \\
\hline II & $\alpha_{1} C h_{t}^{b x \nu_{-} U} \sim \alpha_{2} C h_{t}^{b x \nu_{-} U}$ & $x$ & $\sqrt{ }$ \\
\hline III & $\alpha_{1} C h_{t}^{b g_{2} U} \sim \alpha_{2} C h_{t}^{b g_{-} U}$ & $x$ & $x$ \\
\hline
\end{tabular}

Scenario I: Bi-level approach that optimizes heating sale prices. Scenario II: the ICES operator sets fixed heating sale prices rather than optimizes them. In scenario II, we simulate 10 different heating sale prices from $\alpha_{1} C h_{t}^{b u \nu_{-} U}$ to $\alpha_{2} C h_{t}^{b u \nu_{-} U}$ with a step size of $0.02 \mathrm{Ch}_{t}^{b w}{ }_{-}$. Scenario III: the ICES operator sets the same fixed heating sale prices as in Scenario II. Meanwhile, consumers are not able to adjust their radiators with constant flow rates, thus they cannot provide HDR.

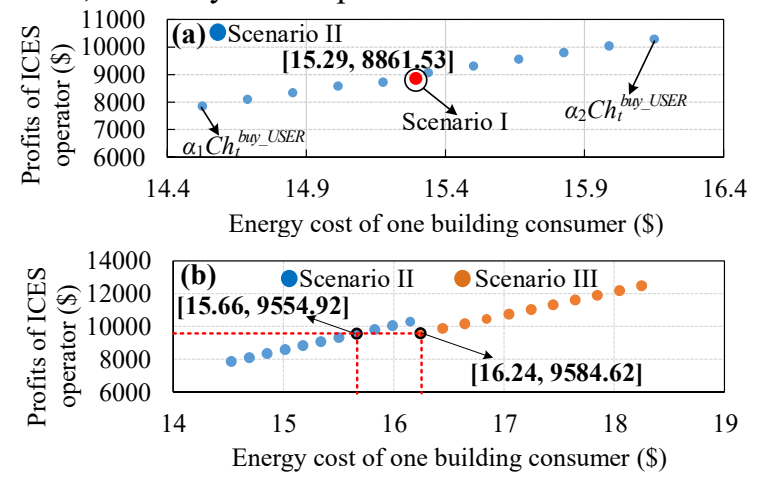

Fig. 14. ICES operator's profit and one consumer's energy cost: (a) scenario I and II; (b) scenario II and III.

To demonstrate the benefits of optimal heating pricing and the bi-level optimization framework, scenario I and II are compared. The profit of the ICES operator and energy cost of one consumer are conflicting in scenario II, as shown in Fig. 14 (a). Specifically, the greater the ICES operator's profit, the higher the energy cost of one consumer, and vice versa. Consequently, scenario II cannot balance the benefits of the ICES operator and consumers with a certain set of fixed heating sale prices (i.e., a certain blue dot in Fig. 14 (a)). In contrast to scenario II, scenario I is the bi-level optimization method that considers the optimal heating pricing between the consumers and the ICES operator. Therefore, a relatively balanced solution (as shown by the red dot in Fig. 14 (a)) can be achieved. This solution benefits the ICES operator and consumers at the same time. As summarized in TABLE V, scenario I is one specific scheme that represents a relatively balanced solution in scenario II.

TABLE V COMPARISONS AMONG THREE SCENARIOS

\begin{tabular}{cccc}
\hline \hline $\begin{array}{c}\text { Scenari } \\
\text { o }\end{array}$ & $\begin{array}{c}\text { Profits of ICES } \\
\text { operator }(\$)\end{array}$ & $\begin{array}{c}\text { Energy cost of } \\
\text { one consumer }\end{array}$ & $\begin{array}{c}\text { Energy cost of all } \\
\text { consumers }(\$)\end{array}$ \\
\hline I & 8861.53 & 15.29 & 25376.99 \\
\hline II & {$[7853.36 \sim 10284.15]$} & {$[14.53 \sim 16.15]$} & {$[24215.73 \sim 26646.52]$} \\
\hline III & {$[9584.62 \sim 12473.00]$} & {$[16.24 \sim 18.25]$} & {$[26274.88 \sim 29163.26]$} \\
\hline \hline
\end{tabular}

To demonstrate the benefits of flexible heating loads of buildings, scenarios II and III are compared. Consumers experience much higher energy costs in scenario III since they are not able to adjust the water flow rates of their radiators, as shown in Fig. 14 (b) and TABLE V. As can be observed from the two specific solutions (i.e., [15.66, 9554.92] in scenario II and $[16.24,9584.62]$ in scenario III) highlighted in Fig. 14 (b), profits of two solutions are almost the same (i.e., only $0.31 \%$ difference between them). However, the energy cost of one consumer of the solution in scenario III is around 3.70\% higher than that in scenario II.

To demonstrate the benefits of the co-optimization of the heating and electricity networks with coupling units (i.e., the CHP and heat pump) in the ICES, scenario IV was carried out. Scenario IV: the CHP and heat pump are not dispatched. Therefore, the heating and electricity networks are not coupled and coordinated in the ICES.

As shown in TABLE VI, compared to Scenario I, the ICES operator has much lower profit and the consumers have higher energy cost in Scenario IV. Therefore, the co-optimization of the heating and electricity networks with coupling units in Scenario I can benefit the ICES operator and the consumers in buildings.

\begin{tabular}{cccc}
\multicolumn{3}{c}{ TABLE VI COMPARISONS BETWEEN SCENARIOS I AND IV } \\
\hline \hline $\begin{array}{c}\text { Scenari } \\
\text { o }\end{array}$ & $\begin{array}{c}\text { Profits of ICES } \\
\text { operator }(\$)\end{array}$ & $\begin{array}{c}\text { Energy cost of } \\
\text { one consumer }\end{array}$ & $\begin{array}{c}\text { Energy cost of all } \\
\text { consumers }(\$)\end{array}$ \\
\hline I & 8861.53 & 15.29 & 25376.99 \\
\hline IV & 3484.67 & 15.53 & 25655.21 \\
\hline \hline
\end{tabular}

\section{B. Case with forecast errors}

In the above base case, perfect forecasts are assumed. In this subsection, the advantages of the MPC method for economic scheduling of the ICES and buildings in the presence of uncertainties are demonstrated. To consider uncertainties of the forecast data, the forecast data are adjusted with a white noise distortion following a Gaussian distribution [33] over each prediction horizon $H_{k}^{p}=\left\{k, k+1, \cdots, k+N_{p}-1\right\}, k=1,2, \cdots, n_{h}$, as shown in (56).

$$
\left\{\begin{array}{c}
\widehat{Y}_{t}=Y_{t}+\delta, \quad t \in N_{k}^{p} \\
\delta \sim N\left(0, \sigma^{2}\right)
\end{array}\right.
$$

where $\widehat{Y}_{t}$ and $Y_{t}$ are the forecasted and accurate values of input data (i.e., wind and PV generation, ICES operator's energy purchase prices, outdoor temperature and solar radiation) at time $t$; and $\delta$ is the forecast error. The mean value of the Gaussian distribution is assumed to be 0 . Different values are set for the maximum forecast standard deviation $\sigma$ in this part 
to represent different forecast errors [33]. Three different values of the $\sigma$ are tested, i.e., $\sigma=0.1 Y_{t}, 0.2 Y_{t}$, and $0.3 Y_{t}$. For each level of $\sigma$, Monte Carlo simulation is conducted to generate the average result of 30 scenarios. Other settings are the same as the base case.

A reference scheme, where the MPC method is not used but the optimization is only conducted once throughout the scheduling day (namely single optimization [14]), is also carried out to demonstrate the benefits of the MPC method.

The scheduling results with two methods with different forecast errors are shown in Fig. 15. It can be observed that both the profits and energy costs with the two methods are decreasing with the increase of the forecast errors. However, the profits of the ICES operator using MPC are higher than that using the single optimization method with different forecast errors. Meanwhile, the energy costs of one consumer using MPC method are lower than that using the single optimization method with different forecast errors. Therefore, both the ICES operator and consumers can benefit more with the proposed MPC method, showing that the MPC method is more advanced than the single optimization method.

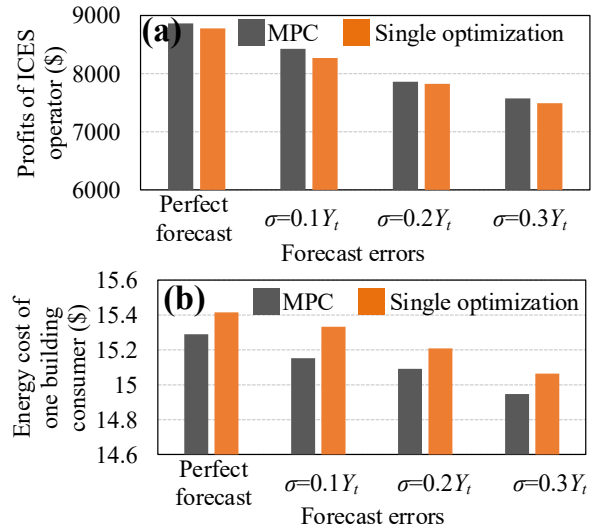

Fig. 15. Comparisons of the two methods with different forecast errors: (a) Operator's profits; (b) Consumers' energy cost.

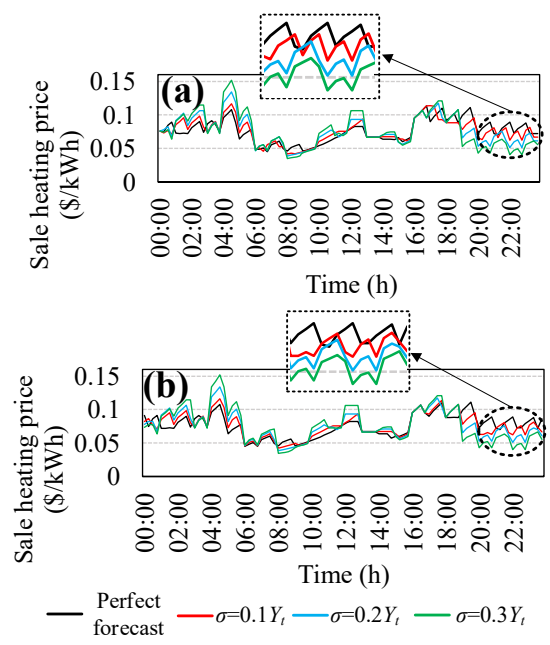

Fig. 16. Optimal heating sale prices with the two methods under different forecast errors: (a) MPC; (b) Single optimization.

As shown in Fig. 16, there are deviations between the optimal heating sale prices with different forecast errors and the optimal heating sale prices with perfect forecast. Moreover, the deviations are increasing with the increase of forecast errors. As analyzed in the base case, the optimal heating sale prices are the key factor that determines the ICES operator's profits and the consumers' energy costs. Consequently, the profits of the ICES operator are decreasing with the increase of forecast errors with both methods.
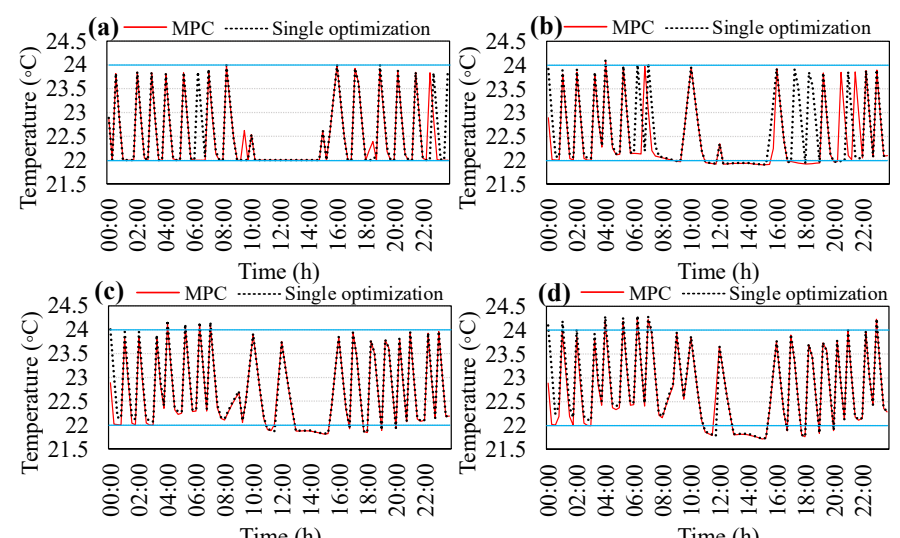

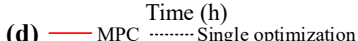

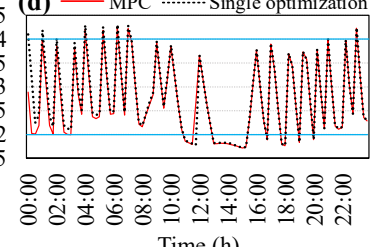

Time (h)

Fig. 17. Actual indoor temperatures of one heating zone with the optimal water flow rates with the two methods.

The optimal indoor temperatures and optimal water flow rates of radiators of consumers are obtained based on the nonperfect forecast data. Therefore, there are deviations between the optimal indoor temperatures and actual indoor temperatures due to forecast errors of the solar radiation and the outdoor temperature. Since indoor temperatures are mainly determined by water flow rates of their radiators, the actual indoor temperatures are simulated using the optimal water flow rates and the actual values of the solar radiation and the outdoor temperature. The results are shown in Fig. 17. The optimal water flow rates used in Fig. 17 (a) (d) are obtained with (a) perfect forecast, (b) forecast with $\sigma=0.1 Y_{t}$, (c) forecast with $\sigma$ $=0.2 Y_{t}$, and (d) forecast with $\sigma=0.3 Y_{t}$, respectively. As can be observed, although the energy costs of consumers are decreasing with the increase of forecast errors (see Fig. 15 (b)), the actual indoor temperatures violate the comfort temperature ranges due to forecast errors. Meanwhile, the violations with both methods are increasing with the increase of forecast errors. Since MPC takes uncertainties into account, the violations are lower and less frequent by using the MPC method than using a single optimization method. This further demonstrates that the MPC method is more advanced than the single optimization method.

\section{CONCLUSION}

This paper proposes a bi-level MPC based optimal integration scheme for consumers in buildings with heating loads in ICES. The ICES operator can optimize the schedules of energy generation and supply, and the heating prices to buildings. Consumers in buildings can minimize their heating costs by optimizing the water flow rates through their radiators based on the heating sale prices. Simulation results show that the proposed bi-level MPC method can obtain a scheduling scheme balancing the ICES operator's profits and energy costs of consumers in buildings. Furthermore, the profits of the ICES 
operator using the MPC are higher than that using a single optimization method for different forecast errors. The energy costs of the consumers in buildings using the MPC are also lower than that using a single optimization method for different forecast errors. Therefore, the MPC method can ensure higher profits for the ICES operator and lower energy costs for consumers in buildings simultaneously.

The future research will be focused on the following aspects:

(1) Develop a multiple-leader and multiple-follower bi-level optimization method to consider multiple energy distribution systems across different utilities at the upper level;

(2) Propose decentralized optimization methods instead of centralized ones for multiple energy distribution systems operated by different entities at the upper level, e.g., the alternating direction method of multipliers (ADMM) approach;

(3) Consider consumers in buildings equipped with renewable generations as a market player. Therefore, the optimal integration of buildings in the ICES considering the electricity trading among the consumers in buildings with pricing strategies will be studied in our future research work.

\section{REFERENCES}

[1] X. Jin, T. Jiang, Y. Mu, C. Long, X. Li, H. Jia, and Z. Li, "Scheduling distributed energy resources and smart buildings of a microgrid via multi-time scale and model predictive control method," IET Renew. Power Gener, vol. 13, no. 6, pp. 816-833, 2019.

[2] EU. Commission staff working document on an EU strategy for heating

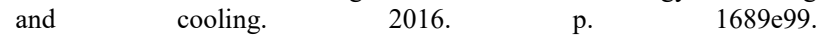
https://doi.org/10.1017/CBO9781107415324.004.

[3] Y. Wang, Y. Wang, Y. Huang, H. Yu, and R. Du, "Optimal Scheduling of the Regional Integrated Energy System Considering Economy and Environment," IEEE Trans. Sustain. Energy, vol. 10, no. 4, pp. 1939 1949, 2019.

[4] M. Wirtz, L. Kivilip, P. Remmen and D. Müller, "5th Generation District Heating: A novel design approach based on mathematical optimization," Appl. Energy, vol. 260, 2020.

[5] T. Jiang, Z. Li, X. Jin, H. Chen, X. Li, and Y. Mu, "Flexible operation of active distribution network using integrated smart buildings with heating, ventilation and air-conditioning systems," Appl. Energy, vol. 226, pp. 181-196, 2018.

[6] R. Zhang, T. Jiang, W. Li, G. Li, H. Chen, and X. Li, "Day-ahead scheduling of integrated electricity and district heating system with an aggregated model of buildings for wind power accommodation," IET Renew. Power Gener, vol.13, pp. 982-989, 2019.

[7] Y. Dai, L. Chen, Y. Min, Q. Chen, J. Hao, K. Hu, and F. Xu, "Dispatch Model for CHP With Pipeline and Building Thermal Energy Storage Considering Heat Transfer Process," IEEE Trans. Sustain. Energy, vol. 10, no. 1, pp. 192-203, 2019.

[8] C. Wu, W. Gu, P. Jiang, Z. Li, H. Cai, and B. Li, "Combined economic dispatch considering the time-delay of district heating network and multi-regional indoor temperature control," IEEE Trans. Sustain. Energy, vol. 9, no. 1, pp. 118-127, 2018.

[9] C. Shao, Y. Ding, P. Siano, and Z. Lin, "A Framework for Incorporating Demand Response of Smart Buildings Into the Integrated Heat and Electricity Energy System," IEEE trans. Ind. Electron., vol. 66, no. 2, pp. 1465-1475, 2019.

[10] H. Cai, C. Ziras, S. You, R. Li, K. Honoré, and H. Bindner, "Demand side management in urban district heating networks," Appl. Energy, vol. 230, pp. 506-518, 2018.

[11] E. Guelpa, L. Marincioni, "Demand side management in district heating systems by innovative control," Energy, vol.188, 2019.

[12] H. Cai, Andreas Thingvad, S. You and Mattia Marinelli, "Experimental evaluation of an integrated demand response program using electric heat boosters to provide multi-system services," Energy, vol. 193, 2020.

[13] W. Gu, J. Wang, S. Lu, Z. Luo, and C. Wu, "Optimal operation for integrated energy system considering thermal inertia of district heating network and buildings," Appl. Energy, vol. 199, pp. 234-246, 2017.
[14] Y. Lu, X. Yu, X. Jin, H. Jia, and Y. Mu, "Bi-level Optimization Framework for Buildings to Heating Grid Integration in Integrated Community Energy Systems," IEEE Trans. Sustain. Energy, published online. DOI: 10.1109/TSTE.2020.3023251.

[15] C. Chen, J. Wang, Y. Heo, and S. Kishore, "MPC-based appliance scheduling for residential building energy management controller," IEEE Trans. Smart Grid, vol. 4, no. 3, pp. 1401-1410, 2013.

[16] M. Pourakbari-Kasmaei, M. Asensio, M. Lehtonen, and J. Contreras, "Trilateral Planning Model for Integrated Community Energy Systems and PV-Based Prosumers-A Bilevel Stochastic Programming Approach," IEEE Trans. Power Syst., vol. 35, no. 1, pp. 346-361, 2020.

[17] C. Mateo, G. Pretticob, T. Gómeza, R. Cossenta, F. Gangaleb, P. Fríasa, and G. Fulli, "European representative electricity distribution networks," Int. J. Electr. Power Energy Syst., vol. 99, pp. 273-280, 2018.

[18] M. Maasoumy, M. Razmara, M. Shahbakhti, and A. S. Vincentelli, "Handling model uncertainty in model predictive control for energy efficient buildings," Energy Build., vol. 77, pp. 377-392, 2014.

[19] R. Tang and S. Wang, "Model predictive control for thermal energy storage and thermal comfort optimization of building demand response in smart grids," Appl. Energy, vol. 242, pp. 873-882, 2019.

[20] Y. Li, C. Feng, F. Wen, K. Wang, and Y. Huang, "Energy pricing and management for park-level energy internets with electric vehicles and power-to-gas devices" Automation of Electric Power Systems, vol. 42, no.16, pp. 192-196, 2018.

[21] H. Gu, Y. Li, J. Yu, C. Wu, T. Song, and J. Xu, "Bi-level optimal lowcarbon economic dispatch for an industrial park with consideration of multi-energy price incentives," Appl. Energy, vol. 262, 2020.

[22] D. Wang, Y. Zhi, H. Jia, K. Hou, S. Zhang, W. Du, X. Wang, and M. Fan, "Optimal scheduling strategy of district integrated heat and power system with wind power and multiple energy stations considering thermal inertia of buildings under different heating regulation modes," Appl. Energy, vol. 240, pp. 341-358, 2019.

[23] H. Yeh, D. F. Gayme and S. H. Low, "Adaptive VAR Control for Distribution Circuits With Photovoltaic Generators," IEEE Trans. Power Syst., vol. 26, no. 3, pp. 1656-1663, 2012.

[24] Z. Li, S. Su, Y. Zhao, X. Jin, H. Chen, Y. Li, and R. Zhang, "Energy management strategy of active distribution network with integrated distributed wind power and smart buildings," IET Renew. Power Gener., vol. 14, no. 12, pp. 2255-2267, 2020.

[25] M. Maasoumy, A. Pinto, and A. Sangiovanni, "Model-Based Hierarchical Optimal Control Design for HVAC Systems," Proceedings of the ASME 2011 Dynamic Systems and Control Conference. eScholarship, University of California, 2014.

[26] Z. Pan, Q. Guo, and H. Sun, "Feasible region method based integrated heat and electricity dispatch considering building thermal inertia," Appl. Energy, vol. 192, pp. 395-407, 2017.

[27] Y. Wang, Y. Dvorkin, R. Fernández-Blanco, B. Xu, T. Qiu, and D. Kirschen, "Look-Ahead Bidding Strategy for Energy Storage," IEEE Trans. Sustain. Energy, vol. 8, no. 3, pp. 1106-1117, 2017.

[28] Y. Du and F. Li, "A Hierarchical Real-Time Balancing Market Considering Multi-Microgrids with Distributed Sustainable Resources," IEEE Trans. Sustain. Energy, vol. 11, no. 1, pp. 72-83, 2020.

[29] C. Shao, X. Wang, M. Shahidehpour, X. Wang, and B. Wang, "An MILPBased Optimal Power Flow in Multicarrier Energy Systems," IEEE Trans. Sustain. Energy, vol. 8, no. 1, pp. 239-248, 2017.

[30] W. Gu, Z. Wang, Z. Wu, Z. Luo, Y. Tang, and J. Wang, "An Online Optimal Dispatch Schedule for CCHP Microgrids Based on Model Predictive Control," IEEE Trans. Smart Grid, vol. 8, no. 5, pp. 23322342, 2017.

[31] X. Yang, Y. Zhang, H. He, S. Ren, and G. Weng, "Real-Time Demand Side Management for a Microgrid Considering Uncertainties," IEEE Trans. Smart Grid, vol. 10, no. 3, pp. 3401-3414, 2019.

[32] W Lin, $X$ Jin, Y. Mu, et al., "A two-stage multi-objective scheduling method for integrated community energy system," Appl. Energy, vol. 216, pp. 428-441, 2018.

[33] Y. Zhou, C. Wang, J. Wu, J. Wang, M. Cheng, and G. Li, "Optimal scheduling of aggregated thermostatically controlled loads with renewable generation in the intraday electricity market," Appl. Energy, vol. 188 , pp. $456-465,2017$. 


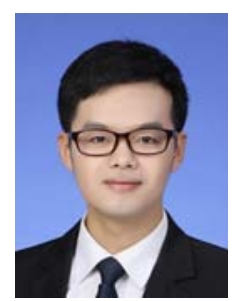

Xiaolong Jin received the B.S., M.S. and Ph.D. degrees in electrical engineering from Tianjin University, China in 2012, 2015 and 2018, respectively.

$\mathrm{He}$ is currently a postdoc researcher with the Centre of Electric Power and Energy, Department of Electrical Engineering, Technical University of Denmark, Lyngby, Denmark. From 2017 to 2019, he was a joint Ph.D. student with the School of Engineering, Cardiff University, Cardiff, UK. His research interests include energy management of multi-energy buildings and their integrations with integrated energy systems, and the energy \& flexibility markets solutions.

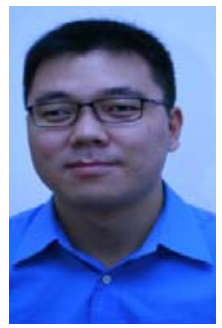

Qiuwei Wu obtained the PhD degree in Power System Engineering from Nanyang Technological University, Singapore, in 2009.

He was a senior R\&D engineer with VESTAS Technology R\&D Singapore Pte Ltd from Mar. 2008 to Oct. 2009. He has been working at Department of Electrical Engineering, Technical University of Denmark (DTU) since Nov. 2009 (PostDoc Nov. 2009-Oct. 2010, Assistant Professor Nov. 2010-Aug. 2013, Associate Professor since Sept. 2013). He was a visiting scholar at Department of Industrial Engineering \& Operations Research (IEOR), University of California, Berkeley, from Feb. 2012 to May 2012 funded by the Danish Agency for Science, Technology and Innovation (DASTI), Denmark. He was a visiting professor named by Y. Xue, an Academician of Chinese Academy of Engineering, at Shandong University, China, from Nov. 2015 to Oct. 2017. He was a visiting scholar at the Harvard China Project, School of Engineering and Applied Sciences, Harvard University from Nov. 2017 - Oct. 2018 funded by the Otto Mønsted Fond. His research interests are operation and control of power systems with high penetration of renewables, including wind power modelling and control, active distribution networks, and operation of integrated energy systems. He is an Editor of IEEE Transactions on Power Systems and IEEE Power Engineering Letters. He is the Deputy Editor-In-Chief of International Journal of Electrical Power and Energy Systems, and an associate Editor of Journal of Modern Power Systems and Clean Energy. He is a subject editor for IET Generation, Transmission \& Distribution, and the regional Editor for Europe of IET Renewable Power Generation.

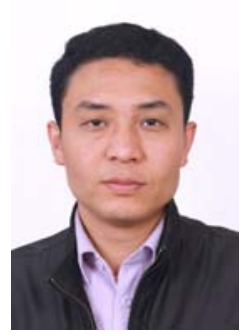

Hongjie Jia received the B.S., M.S., and Ph.D. degrees in electrical engineering from Tianjin University, Tianjin, China, in 1996, 1999, and 2001, respectively. $\mathrm{He}$ is currently a professor with Tianjin University, Tianjin, China. His research interests include power reliability assessment, stability analysis and control, distribution network planning and automation, and integrated energy systems.

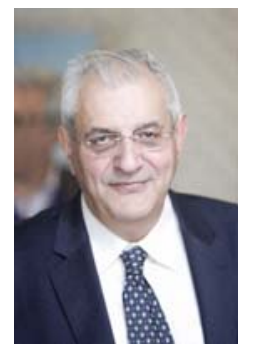

Nikos D. Hatziargyriou is full professor in Power Systems at the Electrical and Computer Engineering School of the National Technical University of Athens. From 2015 to 2019 he was Chair and until 2018, CEO of the Hellenic Distribution Network Operator (HEDNO). From 2007 until 2012 he was executive Vice-Chair and Deputy CEO of the Public Power Corporation (PPC), responsible for the Transmission and Distribution Divisions. He is Fellow Member of IEEE, past Chair of the Power System Dynamic Performance Committee (PSDPC) and currently Editor in Chief of the IEEE Transactions on Power Systems. He is honorary member of CIGRE and past Chair of CIGRE SC C6 "Distribution Systems and Distributed Generation". He was chair and currently vice-chair of the EU Technology and Innovation Platform on Smart Networks for Energy Transition (ETIP-SNET). He has participated in more than $60 \mathrm{RD} \& \mathrm{D}$ projects funded by the EU Commission, electric utilities and manufacturers. He is author of the book "Microgrids: Architectures and Control" and of more than 250 journal publications and 500 conference proceedings papers. He is included in the 2016, 2017 and 2019 Thom-son Reuters lists of the top $1 \%$ most cited researchers. 